\title{
Splanchnic and Renal Exchange of Infused Fructose in Insulin-deficient Type 1 Diabetic Patients and Healthy Controls
}

\author{
Ola Björkman, Rolf Gunnarsson, Eva Hagström, Philip Felig, and John Wahren \\ Departments of Clinical Physiology and Medicine, Huddinge University Hospital, S-141 86 Huddinge, Sweden
}

\begin{abstract}
Fructose raises blood glucose and lactate levels in normal as well as diabetic man, but the tissue origin (liver and/or kidney) of these responses and the role of insulin in determining the end products of fructose metabolism have not been fully established. Splanchnic and renal substrate exchange was therefore examined during intravenous infusion of fructose or saline in six insulin-deficient type I diabetics who fasted overnight and in five healthy controls. Fructose infusion resulted in similar arterial concentrations and regional uptake of fructose in the two groups. Splanchnic glucose output increased threefold in the diabetics but remained unchanged in controls in response to fructose infusion, and the arterial glucose concentration rose more in diabetics $(+5.5 \mathrm{mmol} / \mathrm{liter})$ than in controls $(+0.5$ mmol/liter). Splanchnic uptake of both lactate and pyruvate increased twofold in response to fructose infusion in the diabetics. In contrast, a consistent splanchnic release of both lactate and pyruvate was seen during fructose infusion in controls. In diabetics fructose-induced hyperglycemia was associated with no net renal glucose exchange, while there was a significant renal glucose production during fructose infusion in the controls. In both groups fructose infusion resulted in renal output of lactate and pyruvate. In the diabetics this release corresponded to the augmented uptake by splanchnic tissues. In two diabetic patients given insulin infusion, all responses to fructose infusion were normalized. Fructose infusion in diabetics did not influence either splanchnic ketone body production or its relationship to splanchnic FFA inflow.

We conclude that in insulin-deficient, mildly ketotic type I diabetics, (a) both the liver, by virtue of lactate, pyruvate, and fructose-derived gluconeogenesis, and the kidneys, by virtue of fructose-derived lactate and pyruvate production, contribute to fructose-induced hyperglycemia; (b) glucose production and release rather than formation of lactate, pyruvate, or glycogen, is the major outcome of hepatic fructose metabolism; and (c) fructose does not exert an antiketogenic effect. These data suggest that while total fructose metabolism is not altered in diabetics, intermediary hepatic fructose metabolism is dependent on the presence of insulin.
\end{abstract}

This work was presented in part at the 45th Annual Meeting of the American Diabetes Association, Baltimore, MD, 1985.

Address reprint requests to Dr. John Wahren, Department of Clinical Physiology, Huddinge University Hospital, S-141 86 Huddinge, Sweden.

Received for publication 8 January 1987 and in revised form 1 August 1988.

J. Clin. Invest.

(c) The American Society for Clinical Investigation, Inc. $0021-9738 / 89 / 01 / 0052 / 08 \quad \$ 2.00$

Volume 83, January $1989,52-59$

\section{Introduction}

For more than a century diabetic patients have been known to tolerate fructose better than other sugars (1). This was adequately explained by the findings that fructose uptake by body tissues occurs independently of insulin, as indicated by similar fructose levels attained during infusion in diabetic patients and healthy controls (2-5), and that insulin administration does not affect the rate of fructose metabolism (4). However, there is evidence suggesting that the presence of insulin does affect the control of intermediary metabolism and end points of fructose metabolism. Thus, the fructose-induced changes in lactate, pyruvate, and glucose levels differ between diabetic patients and controls $(2,5,6)$. The site and the mechanism(s) for the different responses have, however, not been clarified.

The liver's major role in the disposal of fructose is well established (6-11). In normal patients who fasted overnight hepatic fructose metabolism is accompanied by variable changes in splanchnic glucose production, a shift from uptake to release of lactate and pyruvate (6-11), and an accumulation of glycogen (12). Only limited information, obtained in three patients showing variable results, is available with regard to measurements of splanchnic (hepatic) fructose metabolism in insulin-deficient diabetics (7). Simultaneous measurements of splanchnic exchange of fructose and three of the potential end products of hepatic fructose metabolism (glucose, lactate, and pyruvate) provide an opportunity to estimate the amount of fructose available for synthesis of other potential end products of hepatic fructose metabolism (glycogen and triglycerides). No studies comparing such estimates in insulin-deficient diabetics and controls are available, nor is it known whether fructose-derived glycogen synthesis is impaired in the diabetic liver.

Apart from the liver, the human kidney possesses the necessary enzymes for the conversion of fructose to lactate and glucose (13). Consistent with this is the finding that in normal subjects who fasted for $60 \mathrm{~h}$, fructose infusion is accompanied by a net renal production of lactate and glucose (14). Whether fructose-derived production by the kidneys contributes to the increased lactate and glucose levels observed in response to fructose infusion in normal subjects who fasted overnight and in diabetic patients has not been determined.

In a previous study Dietze et al. demonstrated that fructose infusion exerts an antiketogenic effect when given intravenously to diabetic patients (15). Since blood ketone levels in these patients were markedly lower than those in insulin-deficient diabetics, it remains to be determined whether the antiketogenic effect of fructose operates under conditions of more severe diabetic acidosis.

In the present study we have examined the following questions: (a) How do the liver and the kidneys interact in the blood glucose and lactate responses to intravenous fructose administration? $(b)$ What is the role of insulin in hepatic fruc- 
tose metabolism? (c) Does fructose infusion exert an antiketogenic effect in insulin-deficient, moderately ketotic diabetic patients?

Measurements of regional (splanchnic and renal) substrate exchange before and during fructose infusion were therefore undertaken in insulin-deficient type I diabetic patients and in healthy subjects. In addition, control studies involving saline infusion in diabetic patients were carried out.

\section{Methods}

Patients and subjects. 11 insulin-dependent diabetic patients and 5 healthy nonobese male volunteers participated in the study. Clinical data for the patients and the control subjects are given in Table I. The nature, purpose, and possible risks involved in the study were carefully explained to the patients and subjects before their voluntary consent to participate was obtained. The procedures were reviewed and approved by the institutional ethics committee.

Procedure. Patients and healthy controls were studied in the morning after a 12-14-h fast. In the patients, the last insulin injection was given $24 \mathrm{~h}$ before the study. Approximately $15 \mathrm{~h}$ before the study intravenous insulin administration was started and continued during the night. Blood glucose was checked every 1-2 h, and if necessary the rate of insulin administration was adjusted to keep blood glucose levels in the range of $10-15 \mathrm{mmol} / \mathrm{liter}$, the rate of infusion varied from 0 to $1.4 \mathrm{U}$ insulin/h. The intravenous insulin administration was discontinued $30 \mathrm{~min}$ before the first measurements in the basal period, corresponding to 60 min before fructose infusion.

Patients and controls came to the laboratory at 8 a.m. Catheters were inserted percutaneously into a brachial or femoral artery, a renal vein, a hepatic vein, and a peripheral vein. The hepatic and renal vein catheters were guided to their positions using fluoroscopic control. Six patients and five controls were studied before and during intravenous fructose infusion at a rate of $4.2 \mathrm{mmol} / \mathrm{min}$ for $60 \mathrm{~min}$. Fructose was given in a $20 \%$ solution. Blood samples were collected from the arterial, renal, and hepatic vein catheters at -15 and $-7.5 \mathrm{~min}$, and immediately before infusion of fructose, and at 40,50 , and $60 \mathrm{~min}$ into the fructose infusion. Arterial blood also was obtained at 15 and $30 \mathrm{~min}$ of infusion. Renal and splanchnic blood flows were estimated by the

Table I. Clinical Data for Diabetic Patients and Control Subjects

\begin{tabular}{|c|c|c|c|c|c|c|}
\hline & Age & Height & Weight & $\begin{array}{l}\text { History of } \\
\text { diabetes }\end{array}$ & $\begin{array}{l}\text { Dose of } \\
\text { insulin }\end{array}$ & $\mathbf{H b A}_{t}$ \\
\hline & $y r$ & $\mathrm{~cm}$ & $k g$ & $y r$ & $U / d$ & $\%$ \\
\hline \multicolumn{7}{|c|}{ Diabetic patients } \\
\hline $\mathbf{A}$ & 37 & 182 & 75 & 7 & 42 & 9.0 \\
\hline B & 31 & 176 & 73 & 19 & 46 & 10.4 \\
\hline $\mathrm{C}$ & 48 & 176 & 71 & 18 & 60 & 9.4 \\
\hline D & 41 & 175 & 77 & 10 & 42 & 13.2 \\
\hline $\mathrm{E}$ & 25 & 183 & 73 & 10 & 48 & 12.5 \\
\hline $\mathbf{F}$ & 46 & 183 & 65 & 4 & 60 & 12.5 \\
\hline G & 42 & 182 & 81 & 10 & 50 & 9.5 \\
\hline $\mathbf{H}$ & 46 & 175 & 74 & 14 & 54 & 9.5 \\
\hline $\mathbf{J}$ & 37 & 176 & 69 & 24 & 38 & 6.4 \\
\hline $\mathbf{K}$ & 54 & 176 & 75 & 23 & 45 & 8.0 \\
\hline $\mathbf{L}$ & 24 & 189 & 83 & 15 & 66 & 8.9 \\
\hline $\mathbf{M}$ & 30 & 183 & 71 & 6 & 24 & 4.2 \\
\hline \multicolumn{7}{|c|}{ Healthy controls* } \\
\hline$n=5$ & $\begin{array}{c}29 \\
(21-34)\end{array}$ & $\begin{array}{c}175 \\
(168-183)\end{array}$ & $\begin{array}{c}70 \\
(67-74)\end{array}$ & - & - & - \\
\hline
\end{tabular}

* Data given as mean and range. constant infusion technique, using infusion of para-amino hippurate (16) and indocyanine green dye (17), respectively. Renal and splanchnic substrate exchanges were calculated as the arterial-venous concentration difference times the respective estimated blood flow. Average substrate exchange in the basal state and during the last $20 \mathrm{~min}$ of fructose infusion was calculated from three measurements taken at 7.5-10-min intervals.

To examine the effect of insulin deficiency alone, five diabetic patients (four of them previously studied with fructose infusion) were studied on a separate occasion with infusion of saline instead of fructose. Arterial samples were collected before, during, and after saline infusion for analysis of substrate concentrations.

Two of the diabetic patients were studied again during fructose infusion with concomitant insulin infusion. The protocol comprised a continuation of the overnight intravenous insulin administration during the basal period and infusion of insulin at an increased rate of 0.5 $\mathrm{mU} / \mathrm{min}$ per $\mathrm{kg}$ during fructose infusion. Measurements of splanchnic but not renal substrate exchange were obtained before and during fructose infusion in these two patients.

Analytical methods. Glucose was analyzed in whole blood by the glucose-oxidase method (18). Fructose (19), lactate (20), pyruvate (21), glycerol (22), acetoacetate, and $\beta$-OH-butyrate (23) were all determined enzymatically in whole blood by methods adapted for fluorometry. FFA concentration was measured by gas chromatography with heptadecanoic acid as an internal standard (24). Individual amino acids were measured in whole blood by an automated ion exchange chromatograph (Liquimat III; Kontron Elektronik GmbH, Zurich, Switzerland) using a single column of Aminex 9 (Bio-Rad Laboratories, Richmond, CA) and lithium pico buffer system W (Durrum Chemical Corp., Sunnyvale, CA). Insulin was analyzed by RIA (as free insulin in diabetics after pretreatment with $25 \%$ polyethylene glycol). Norepinephrine and epinephrine were measured by the HPLC technique using electrochemical detection (25): C-Peptide was determined in the diabetic patients by RIA. Blood oxygen saturation was determined using a hemoximeter $\left(\mathrm{OSM}_{2}\right.$; Radiometer, Copenhagen, Denmark) and hemoglobin was analyzed using the cyanmethemoglobin method. Blood oxygen content was calculated as the product of hemoglobin concentration and oxygen saturation, assuming $1.34 \mathrm{ml}$ oxygen $/ \mathbf{g}$ hemoglobin.

Statistical methods. All data are presented as the mean \pm SEM. All statistical comparisons between groups were made with unpaired $t$ test. Changes in response to fructose infusion within any given group were evaluated with paired $t$ test. Coefficients of correlation were determined by standard procedures.

\section{Results}

\section{Before fructose infusion}

In the diabetics, $30 \mathrm{~min}$ after the cessation of the overnight insulin infusion the arterial glucose concentrations ranged from 3.8 to $16.5 \mathrm{mmol} /$ liter (mean value $12.1 \pm 2.0 \mathrm{mmol} /$ liter); in control subjects the basal glucose concentration was $4.1 \pm 0.1 \mathrm{mmol} /$ liter. The arterial $\beta$-OH-butyrate and acetoacetate concentrations were 8-11-fold higher than in controls and amounted to $0.98 \pm 0.17$ (range $0.5-1.8$ ) and $0.49 \pm 0.13$ (range $0.2-1.1) \mathrm{mmol} / \mathrm{liter}$, respectively. The arterial levels of glycerol $(0.08 \pm 0.01 \mathrm{mmol} / \mathrm{liter})$ and FFA $(0.91 \pm 0.15 \mathrm{mmol} / \mathrm{liter})$ were both twofold higher than in healthy controls. No differences between patients and controls were observed for the other measured substrates.

\section{Fructose infusion}

Fructose. Fructose infusion resulted in a gradual rise in fructose concentration in controls and diabetics, reaching an average level of $3.2 \pm 0.2 \mathrm{mmol} / \mathrm{liter}$ at $40-60 \mathrm{~min}$ of infusion (Fig. 1). Of the fructose infused $(4.2 \mathrm{mmol} / \mathrm{min})$ in both groups, 


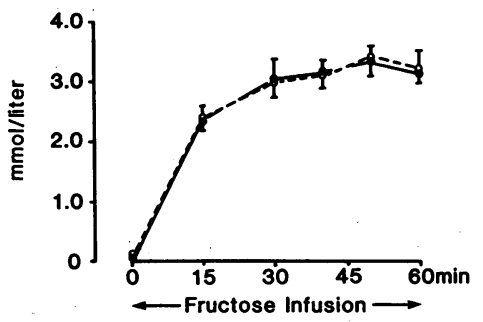

Figure 1. Arterial fructose concentrations in the basal state and during fructose infusion in diabetic patients and control subjects.

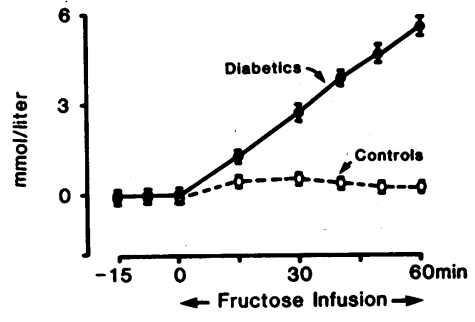

$17-21 \%$ was taken up by the kidneys (diabetics $0.7 \pm 0.2$ $\mathrm{mmol} / \mathrm{min}$, controls $0.9 \pm 0.1 \mathrm{mmol} / \mathrm{min}$ ) and $43-48 \%$ was extracted by the splanchnic tissues (diabetics $2.1 \pm 0.2 \mathrm{mmol} /$ min, controls $1.8 \pm 0.1 \mathrm{mmol} / \mathrm{min}$ ).

Glucose. Although the glucose concentration varied before the infusion (Fig. 2), the change in blood glucose levels in response to fructose was much the same in all patients (5.5 $\pm 0.4 \mathrm{mmol} /$ liter; range $4.6-7.1 ; P<0.001)$. This increase was 3.5-fold higher than that observed during saline infusion (1.5 $\pm 0.4 \mathrm{~mol} / \mathrm{liter}$, Fig. 2). In healthy subjects, on the other hand, the arterial glucose concentration rose only transiently and by much less in response to fructose $(+0.5 \mathrm{mmol} /$ liter at 15-30 min; $P<0.01$ ) and returned to baseline values by the end of the infusion (Fig. 3).

Fructose infusion in diabetics was accompanied by a threefold rise in splanchnic glucose output, while no effect on glucose production was observed in controls (Fig. 3). In the diabetics mean renal glucose exchange before fructose infusion was $0.46 \pm 0.27 \mathrm{mmol} / \mathrm{min}$, a value not significantly different from zero. Of the six patients studied, the two with fasting glucose values of 3.8 and $8.8 \mathrm{mmol} / \mathrm{liter}$ showed a net renal glucose output (both $-0.04 \mathrm{mmol} / \mathrm{min}$ ). In the remaining four patients basal glucose values in the range 13.5-16.5 mmol/liter were accompanied by renal glucose uptake ranging from 0.2 to $1.3 \mathrm{mmol} / \mathrm{min}$. In the controls basal renal glucose exchange $(0.05 \pm 0.03 \mathrm{mmol} / \mathrm{min})$ was not different from zero.

The fructose-induced rise in glucose levels in the diabetics was accompanied by an increase in mean renal glucose uptake to $0.75 \pm 0.36 \mathrm{mmol} / \mathrm{min}$ (NS). In five patients, all having blood glucose levels in excess of $15.9 \mathrm{mmol} / \mathrm{liter}$ at the end of fructose infusion, renal glucose uptake ranged from 0.07 to $1.61 \mathrm{mmol} / \mathrm{min}$. In one patient the blood glucose concentra-
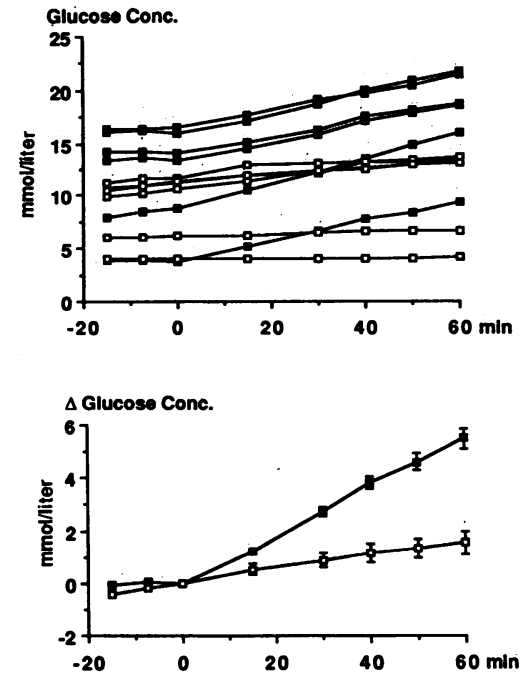

Figure 2. Individual values (top) and mean \pm SEM (bottom) of arterial glucose concentration in the basal state and during infusion of fructose (solid squares) or saline (open squares) in insulin-deficient diabetic patients.

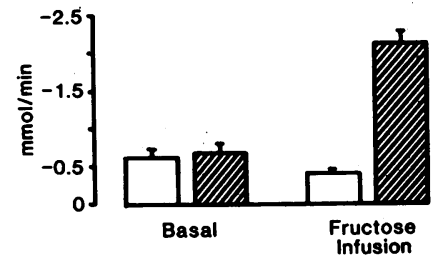

Figure 3. (Top) Increase in arterial glucose concentration in response to fructose infusion in diabetic patients and control subjects. (Middle) splanchic and (bottom) renal glucose exchange in the basal state and during fructose infusion in diabetic patients and control subjects. tion reached $9.4 \mathrm{mmol} / \mathrm{liter}$ and a renal glucose release of 0.12 $\mathrm{mmol} / \mathrm{min}$ (threefold higher than basal) was observed. In controls, fructose infusion was accompanied by a shift from no net exchange to a significant renal glucose release $(-0.22 \pm 0.02$ $\mathrm{mmol} / \mathrm{min} ; \dot{P}<0.001$ compared with the basal state).

Gluconeogenic precursors. In the diabetics the arterial lactate level doubled $(P<0.001)$ in response to fructose infusion, while in controls it rose fivefold $(P<0.001)$, reaching levels $160 \%$ above those in diabetics $(P<0.001$; Fig. 4$)$.
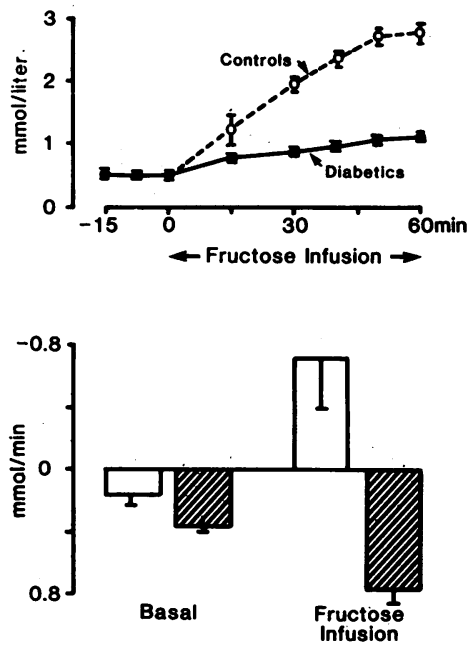

Figure 4. (Top) Arterial lactate concentration in response to fructose infusion in diabetic patients and control subjects. (Middle) splanchnic and (bottom) renal lactate exchange in the basal state and during fructose infusion in diabetic patients and control subjects. 
Table II. Arterial Concentrations of Substrates in the Basal State and during Fructose Infusion in Type I Diabetic Patients (D) and in Healthy Controls (C)

\begin{tabular}{|c|c|c|c|c|c|}
\hline & & Basal & $P$ & $\begin{array}{l}\text { Fructose } \\
\text { infusion }\end{array}$ & $P$ \\
\hline & & \multicolumn{2}{|c|}{ mmol/liter } & \multicolumn{2}{|c|}{ mmol/liter } \\
\hline \multirow[t]{2}{*}{ Pyruvate } & D & $0.04 \pm 0.01$ & \multirow{2}{*}{ NS } & $0.08 \pm 0.01 *$ & \multirow{2}{*}{$<0.001$} \\
\hline & $\mathrm{C}$ & $0.05 \pm 0.01$ & & $0.23 \pm 0.01^{\ddagger}$ & \\
\hline \multirow[t]{2}{*}{ Alanine } & D & $0.19 \pm 0.01$ & \multirow{2}{*}{ NS } & $0.23 \pm 0.01^{\S}$ & \multirow{2}{*}{$<0.001$} \\
\hline & $\mathrm{C}$ & $0.26 \pm 0.03$ & & $0.39 \pm 0.02^{*}$ & \\
\hline \multirow[t]{2}{*}{ Glycerol } & D & $0.08 \pm 0.01$ & \multirow[t]{2}{*}{$<0.05$} & $0.14 \pm 0.01^{\ddagger}$ & \multirow{2}{*}{$<0.001$} \\
\hline & $\mathrm{C}$ & $0.04 \pm 0.01$ & & $0.04 \pm 0.01$ & \\
\hline \multirow[t]{2}{*}{ Acetoacetate } & D & $0.49 \pm 0.13$ & \multirow{2}{*}{$<0.05$} & $0.51 \pm 0.16$ & \multirow{2}{*}{$<0.05$} \\
\hline & C & $0.06 \pm 0.01$ & & $0.02 \pm 0.01^{\S}$ & \\
\hline \multirow[t]{2}{*}{$\beta$-OH-butyrate } & D & $0.98 \pm 0.17$ & \multirow[t]{2}{*}{$<0.01$} & $0.86 \pm 0.14$ & \multirow{2}{*}{$<0.001$} \\
\hline & $\mathrm{C}$ & $0.09 \pm 0.03$ & & $0.02 \pm 0.01$ & \\
\hline \multirow[t]{2}{*}{ FFA } & D & $0.91 \pm 0.18$ & \multirow{2}{*}{$<0.05$} & $1.33 \pm 0.15^{*}$ & \multirow{2}{*}{$<0.001$} \\
\hline & C & $0.43 \pm 0.06$ & & $0.23 \pm 0.03^{8}$ & \\
\hline
\end{tabular}

Values are means \pm SEM. $P$ values denote a significant difference between $\mathrm{D}$ and $\mathrm{C}$ (unpaired $t$ test). Significantly different from the corresponding value in the basal state: ${ }^{*} P<0.001,{ }^{\ddagger} P<0.01,{ }^{\S} P<0.05$.

Splanchnic lactate uptake tended to be higher in the diabetics but the difference did not reach statistical significance (diabetics $0.36 \pm 0.03$, controls $0.16 \pm 0.07$ ). In the diabetics splanchnic lactate uptake rose twofold in response to fructose infusion $(P<0.01)$, whereas in all control subjects a significant net splanchnic release was observed after fructose $(-0.72 \pm 0.32$ $\mathrm{mmol} / \mathrm{min}$; range -0.12 to -1.97 ).
Renal lactate exchange changed in both groups from an insignificant uptake in the basal state to a significant net output during fructose infusion (diabetics from $0.04 \pm 0.03-$ $-0.42 \pm 0.06 \mathrm{mmol} / \mathrm{min}, P<0.01$; controls from $0.02 \pm 0.02$ $-0.29 \pm 0.06 \mathrm{mmol} / \mathrm{min}, P<0.01$ ).

The changes in arterial concentration and regional exchange of pyruvate were much the same as those observed for lactate. Thus, in the diabetics fructose infusion resulted in a doubling of both the arterial pyruvate levels and the splanchnic uptake of pyruvate, while in controls the pyruvate concentration rose more markedly (4.5-fold) in association with a splanchnic pyruvate release (Tables II and III).

Renal pyruyate exchange was close to zero in the basal state, but in both groups fructose infusion led to a significant release that reached a significantly higher rate in the diabetics (Table III).

In the diabetics the elevated basal arterial concentration of glycerol was accompanied by a twofold higher splanchnic uptake of glycerol compared with controls (Tables II and III). Renal glycerol uptake was not statistically different in the two groups. In the diabetics fructose infusion was accompanied by parallel increments in arterial levels (twofold) as well as in splanchnic (2.3-fold) and renal uptake (1.5-fold) of glycerol. In contrast, no significant influence of fructose infusion on these variables was observed in controls.

FFA and ketone bodies. In the diabetics fructose infusion was accompanied by a $45 \%$ increase in the arterial concentration of FFA. In contrast, FFA levels in controls were not only lower than in diabetics in the basal state, but also fell to half the basal value during fructose administration. As a result, the FFA concentration during fructose infusion was $<20 \%$ of the corresponding value in diabetics.

The elevated arterial levels of acetoacetate and $\beta$-OH-buty-

Table III. Substrate Exchange and Estimated Blood Flow across Splanchnic and Renal Tissues in Type I Diabetic Patients (D) and in Healthy Controls (C)

\begin{tabular}{|c|c|c|c|c|c|c|c|c|c|}
\hline & & \multicolumn{4}{|c|}{ Splanchnic exchange } & \multicolumn{4}{|c|}{ Renal exchange } \\
\hline & & Basal & $P$ & Fructose infusion & $P$ & Basal & $P$ & Fructose infusion & $P$ \\
\hline & & \multicolumn{4}{|c|}{$\mathrm{mmol} / \mathrm{min}$} & \multicolumn{4}{|c|}{$\mathrm{mmol} / \mathrm{min}$} \\
\hline \multirow[t]{2}{*}{ Pyruvate } & D & $0.03 \pm 0.01$ & \multirow{2}{*}{ NS } & $0.06 \pm 0.01^{*}$ & \multirow{2}{*}{$<0.01$} & $-0.01 \pm 0.01$ & \multirow{2}{*}{ NS } & $-0.04 \pm 0.01^{\ddagger}$ & \multirow{2}{*}{$<0.01$} \\
\hline & $\mathrm{C}$ & $0.00 \pm 0.01$ & & $-0.22 \pm 0.07$ & & $0.01 \pm 0.01$ & & $-0.01 \pm 0.01^{\S}$ & \\
\hline \multirow[t]{2}{*}{ Alanine } & D & $0.10 \pm 0.01$ & \multirow{2}{*}{ NS } & $0.12 \pm 0.02$ & \multirow{2}{*}{$<0.01$} & $-0.02 \pm 0.01$ & \multirow{2}{*}{ NS } & $-0.03 \pm 0.01$ & \multirow{2}{*}{ NS } \\
\hline & $\mathrm{C}$ & $0.08 \pm 0.01$ & & $0.02 \pm 0.01$ & & $-0.01 \pm 0.01$ & & $-0.02 \pm 0.01$ & \\
\hline \multirow[t]{2}{*}{ Glycerol } & $\mathrm{D}$ & $0.09 \pm 0.02$ & \multirow{2}{*}{$<0.05$} & $0.21 \pm 0.03^{\ddagger}$ & \multirow{2}{*}{$<0.001$} & $0.05 \pm 0.02$ & \multirow{2}{*}{ NS } & $0.07 \pm 0.01$ & \multirow{2}{*}{$<0.001$} \\
\hline & $\mathrm{C}$ & $0.04 \pm 0.01$ & & $0.03 \pm 0.01$ & & $0.02 \pm 0.01$ & & $0.01 \pm 0.01$ & \\
\hline \multirow[t]{2}{*}{ Acetoacetate } & D & $-0.41 \pm 0.12$ & \multirow{2}{*}{$<0.05$} & $-0.68 \pm 0.27$ & \multirow{2}{*}{ NS } & $0.05 \pm 0.03$ & \multirow{2}{*}{ NS } & $0.04 \pm 0.01$ & \multirow{2}{*}{$<0.05$} \\
\hline & $\mathrm{C}$ & $-0.07 \pm 0.02$ & & $-0.03 \pm 0.01$ & & $0.00 \pm 0.01$ & & $0.00 \pm 0.01$ & \\
\hline \multirow[t]{2}{*}{$\beta$-OH-butyrate } & D & $-0.35 \pm 0.09$ & \multirow{2}{*}{$<0.05$} & $-0.35 \pm 0.09$ & \multirow{2}{*}{$<0.01$} & $0.08 \pm 0.02$ & \multirow{2}{*}{$<0.05$} & $0.07 \pm 0.02$ & \multirow{2}{*}{$<0.05$} \\
\hline & $\mathrm{C}$ & $-0.07 \pm 0.03$ & & $-0.01 \pm 0.01$ & & $0.02 \pm 0.01$ & & $0.00 \pm 0.01^{\S}$ & \\
\hline \multirow[t]{3}{*}{ Oxygen } & D & $1.88 \pm 0.16$ & \multirow{2}{*}{$<0.05$} & $2.53 \pm 0.18^{*}$ & \multirow{2}{*}{$<0.001$} & $0.63 \pm 0.09$ & \multirow{2}{*}{ NS } & $0.52 \pm 0.04$ & \multirow{2}{*}{ NS } \\
\hline & $\mathrm{C}$ & $1.30 \pm 0.09$ & & $1.25 \pm 0.11$ & & $0.42 \pm 0.04$ & & $0.39 \pm 0.04$ & \\
\hline & & \multicolumn{4}{|c|}{ liter/min } & & & $\min$ & \\
\hline Blood flow & D & $1.44 \pm 0.13$ & NS & $1.48 \pm 0.13$ & NS & $1.43 \pm 0.14$ & NS & $1.28 \pm 0.12^{*}$ & NS \\
\hline & $\mathrm{C}$ & $1.38 \pm 0.08$ & IV & $1.24 \pm 0.10$ & & $1.42 \pm 0.12$ & & $1.19 \pm 0.12^{*}$ & \\
\hline
\end{tabular}

Values are means \pm SEM. $P$ values denote a significant difference between $\mathrm{D}$ and $\mathrm{C}$ (unpaired $t$ test). Significantly different from the corresponding value in the basal state: ${ }^{*} P<0.001,{ }^{\ddagger} P<0.01,{ }^{\S} P<0.05$. 
rate in the diabetics were accompanied by a five- to sixfold higher splanchnic ketone body production compared with controls (Tables II and III). In the diabetic patients splanchnic production of ketone bodies was unchanged during fructose infusion, while in the controls it fell to $\sim$ one-third of the already low value observed in the basal state. Total splanchnic ketone body production was significantly correlated to the splanchnic FFA inflow (calculated as splanchnic plasma flow times the arterial concentration of acetoacetate plus $\beta$-OH-butyrate) in both diabetics and controls (Fig. 5).

Amino acids. Before fructose infusion the arterial concentration and splanchnic uptake of alanine did not differ between the two groups (Tables II and III). Renal alanine exchange indicated a minimal release in both groups (Table III). Fructose infusion was accompanied by a rise in arterial alanine levels in both groups but this response was more pronounced in controls, resulting in $70 \%$ higher values than in the diabetics. In the diabetics splanchnic alanine exchange remained unchanged in response to fructose infusion, while a $70 \%$ fall was observed in controls. Renal alanine exchange was not influenced by fructose infusion in either of the groups. In the diabetics the arterial concentrations of branched-chain amino acids (valine, leucine, and isoleucine) tended to be higher than those in healthy controls, in accordance with previous reports (26). These amino acids varied considerably in relation to the particular patient's metabolic control. Thus, the concentration of total branched-chain amino acids was significantly correlated to the acetoacetate level $(r=0.98, P<0.001)$. The concentrations of all other amino acids did not differ between diabetics and controls. Splanchnic and renal exchanges of amino acids before fructose infusion were also similar in diabetics and controls. Apart from the effects on the level and splanchnic exchange of alanine, fructose infusion exerted only a minor influence on the concentration and splanchnic exchange of other amino acids. No effect of fructose infusion was observed on the renal exchange of any amino acid.

Hormone concentrations, blood flows, blood gases, and regional oxygen exchange. All diabetic patients had undetectable C-peptide levels ( $<0.05 \mathrm{nmol} / \mathrm{liter})$. Arterial insulin concentration in controls rose from $5 \pm 1$ in the basal state to $10 \pm 1$ $\mu \mathrm{U} / \mathrm{ml}$ during fructose infusion $(P<0.01)$. The arterial epinephrine concentration (basal state, diabetics $0.38 \pm 0.08$, controls $0.38 \pm 0.06 \mathrm{nmol} / \mathrm{liter}$ ) was not influenced by fructose in-
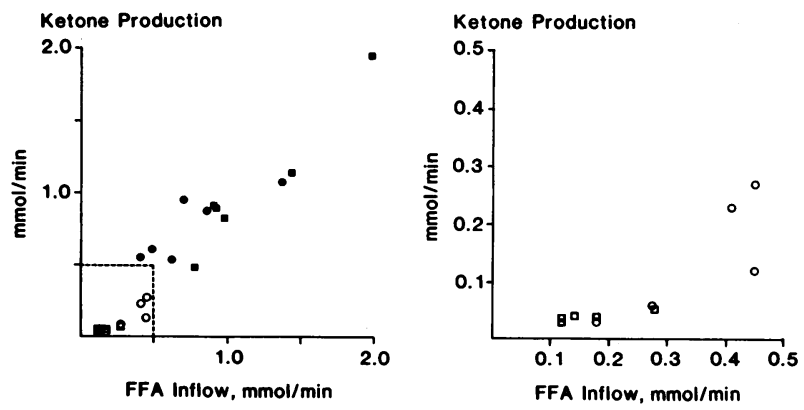

Figure 5. Relationship between splanchnic FFA inflow and ketone body production (the sum of acetoacetate and $\beta$-hydroxybutyrate). (Right) An expanded view of data in the basal state. Symbols for diabetics: solid circles, basal state; solid squares, fructose infusion. Symbols for controls: open circles, basal state; open squares, fructose infusion. fusion. The arterial norepinephrine level in the diabetics tended to exceed that in control subjects (basal state $1.34 \pm 0.24$ vs. $0.76 \pm 0.10 \mathrm{nmol} /$ liter, NS; fructose infusion $1.57 \pm 0.24$ vs. $0.89 \pm 0.14 \mathrm{nmol} / \mathrm{liter}, P<0.05$ ). Splanchnic blood flow was similar in diabetic patients and controls and no significant changes were observed in response to fructose infusion in either group (Table III). Renal blood flow was similar in the two groups in the basal state and fell slightly $(-10--15 \%)$ and to the same extent after fructose infusion (Table III).

In the diabetics arterial $\mathrm{pH}$ in the basal state was $7.39 \pm 0.01$ and fell to $7.35 \pm 0.01$ in response to fructose infusion $(P$ $<0.001)$. In controls basal arterial $\mathrm{pH}(7.37 \pm 0.01)$ did not differ from that in diabetics but fructose infusion failed to influence $\mathrm{pH}$.

Splanchnic oxygen uptake rose in diabetic patients from $1.9 \pm 0.2$ to $2.5 \pm 0.2 \mathrm{mmol} / \mathrm{min}(P<0.001)$ in response to fructose infusion (Table III). In controls the uptake was $30 \%$ lower than in the patients $(1.3 \pm 0.1 \mathrm{mmol} / \mathrm{min})$ and showed no significant influence from fructose infusion.

Basal renal oxygen uptake did not differ between diabetics and controls and did not change significantly during fructose infusion in either group (Table III).

Saline infusion. The arterial glucose level rose gradually during $60 \mathrm{~min}$ of saline infusion $(1.5 \pm 0.4 \mathrm{mmol} / \mathrm{liter}$; range 0.08-2.91 mmol/liter, Fig. 2). The basal arterial levels of lactate $(0.44 \pm 0.05 \mathrm{mmol} / \mathrm{liter})$, pyruvate $(40 \pm 4 \mu \mathrm{mol} / \mathrm{liter})$, and glycerol ( $93 \pm 12 \mu \mathrm{mol} /$ liter) remained unchanged during saline infusion while the concentration of $\beta-\mathrm{OH}$-butyrate rose from $0.64 \pm 0.12 \mathrm{mmol} /$ liter to $0.91 \pm 0.24 \mathrm{mmol} /$ liter after $60 \mathrm{~min}$ of saline infusion.

Fructose infusion with insulin replacement. Two of the diabetic patients participated in a study comprising fructose infusion during continued insulin administration. The free insulin level reached 22 and $29 \mu \mathrm{U} / \mathrm{ml}$, respectively. In these patients essentially all metabolic responses to fructose infusion were within the range observed in control subjects. Thus, the arterial glucose concentration remained unchanged or fell in response to fructose infusion, while the lactate level rose substantially. Splanchnic glucose production was normalized and there was a release of lactate and pyruvate (Table IV).

\section{Discussion}

In the present study diabetic patients were examined in the acutely insulin-deficient state. In this metabolic condition one would expect the arterial glucose concentration to rise with time as a consequence of gradually increasing glucose production and decreasing glucose uptake. It could thus be argued that the rise in splanchnic glucose output and the accompanying increase in glucose level during fructose infusion were an effect of insulin deficiency per se rather than a response to the fructose infusion. However, several lines of evidence indicate that the observed increases in splanchnic glucose output and concentration were primarily due to the effect of the fructose infusion. First, in the control study comprising infusion of saline instead of fructose to the diabetics, the arterial glucose concentration rose by $1.5 \pm 0.4 \mathrm{mmol} / \mathrm{liter}$, or no more than $27 \%$ of the increase observed during fructose infusion. Second, the rate of splanchnic glucose output observed during fructose infusion $(2.1 \mathrm{mmol} / \mathrm{min})$ greatly exceeds the noninfusion output reported in diabetic patients with a comparable degree of 
Table IV. Changes in Arterial Concentrations and Splanchnic Exchange of Substrates during Fructose Infusion in Two Diabetic Patients with and without Insulin Infusion

\begin{tabular}{|c|c|c|c|c|}
\hline & \multicolumn{2}{|c|}{ Patient A } & \multicolumn{2}{|c|}{ Patient B } \\
\hline & $\begin{array}{l}\text { Fructose } \\
\text { infusion }\end{array}$ & $\begin{array}{l}\text { Fructose } \\
+ \text { insulin } \\
\text { infusion }\end{array}$ & $\begin{array}{l}\text { Fructose } \\
\text { infusion }\end{array}$ & $\begin{array}{l}\text { Fructose } \\
+ \text { insulir } \\
\text { infusion }\end{array}$ \\
\hline & \multicolumn{4}{|c|}{ mmol/liter } \\
\hline \multicolumn{5}{|c|}{ Arterial concentration } \\
\hline Fructose & +2.89 & +2.88 & +3.00 & +3.23 \\
\hline Glucose & +7.11 & +0.44 & +5.74 & -2.89 \\
\hline Lactate & +0.53 & +2.23 & +0.42 & +1.61 \\
\hline Pyruvate & +0.04 & +0.16 & +0.03 & +0.11 \\
\hline Alanine & +0.05 & +0.17 & -0.02 & +0.11 \\
\hline \multirow[t]{2}{*}{ Glycerol } & -0.08 & 0 & +0.05 & -0.01 \\
\hline & \multicolumn{4}{|c|}{$\mathrm{mmol} / \mathrm{min}$} \\
\hline \multicolumn{5}{|c|}{ Splanchnic uptake* } \\
\hline Fructose & 2.39 & 2.23 & 2.20 & 1.84 \\
\hline Lactate & 0.35 & - & 0.18 & - \\
\hline Pyruvate & 0.04 & - & 0.03 & - \\
\hline Alanine & 0.07 & 0 & 0.08 & 0.02 \\
\hline Glycerol & 0.15 & 0.02 & 0.15 & 0.01 \\
\hline Total uptake & 3.00 & 2.25 & 2.64 & 1.87 \\
\hline \multicolumn{5}{|c|}{ Splanchnic release* } \\
\hline Glucose & 2.74 & 0.68 & 2.26 & 0.22 \\
\hline Lactate & - & 0.16 & - & 0.21 \\
\hline Pyruvate & - & 0.04 & - & 0.08 \\
\hline \multicolumn{5}{|l|}{ Total splanchnic } \\
\hline release* & 2.74 & 0.88 & 2.26 & 0.51 \\
\hline Uptake release* & 0.26 & 1.37 & 0.38 & 1.36 \\
\hline
\end{tabular}

* Data are expressed as glucose equivalents.

insulin deficiency (26). Third, the threefold rise in glucose output in response to fructose occurred within a relatively short period of time (40-60 min). Fourth, splanchnic substrate balance data are compatible with fructose-derived glucose production: fructose uptake could account for the entire glucose output (Table V) and no release of lactate or pyruvate was observed, indicating net substrate flux in the direction of gluconeogenesis. These considerations indicate that although insulin deficiency per se may contribute to the observed increments in arterial glucose levels and splanchnic glucose output, fructose-derived increases in glucose production play a dominant role in the hyperglycemic response.

Infusion of fructose resulted in similar arterial levels (Fig. 1), splanchnic uptake, and renal uptake of fructose in the insulin-deficient diabetics and controls, thus confirming previous reports that the rate of fructose disposal is independent of the presence of insulin (4). However, despite an indistinguishable rate of splanchnic uptake in diabetics and controls, the end products of splanchnic fructose metabolism (occurring mainly in the liver) were quite different. Thus, in the diabetics fructose administration resulted in increased glucose production (threefold), augmented arterial glucose levels $(5.5 \mathrm{mmol} /$ liter), and elevated, continued uptakes of lactate and pyruvate (Figs. 3 and 4, Table III). In contrast, fructose infusion in
Table V. Splanchnic Metabolism of Infused Fructose in Normal Man and Insulin-deficient Type 1 Diabetic Patients

\begin{tabular}{lcc}
\hline & Controls & Diabetics \\
\hline Uptake & mmol/min & mmol/min \\
Fructose & 1.84 & \\
Lactate & - & 2.06 \\
Pyruvate & - & 0.39 \\
Alanine & 0.01 & 0.03 \\
Glycerol & 0.02 & 0.06 \\
Total uptake & 1.87 & 0.10 \\
Release & & 2.64 \\
Glucose & 0.41 & \\
Lactate & 0.36 & 2.12 \\
Pyruvate & 0.11 & - \\
Total release & 0.88 & - \\
Uptake release & 0.99 & 2.12 \\
\end{tabular}

Data are expressed as glucose equivalents.

control subjects was accompanied by unchanged splanchnic glucose production, a minimal rise in glucose concentration, and significant splanchnic releases of lactate and pyruvate resulting in fivefold augmented arterial levels of these compounds. These contrasting responses indicate that, while the rate of fructose uptake by splanchnic tissues is not influenced by insulin, intrahepatic fructose metabolism is regulated by insulin such that insulin deficiency markedly stimulates fructose-derived hepatic glucose production. In contrast, in the presence of insulin the end products of hepatic fructose metabolism released by the liver are lactate and pyruvate. A possible role for glucagon in this context cannot be excluded, but the above conclusion is further supported by the normalization of the fructose-induced changes in splanchnic glucose, lactate, and pyruvate exchange in the two diabetic patients receiving an insulin infusion in conjunction with the fructose administration (Table IV).

In the diabetics splanchnic fructose uptake during infusion was accompanied by increased uptakes of lactate, pyruvate, and glycerol in association with augmented levels of these metabolites. In addition, splanchnic alanine uptake continued. The augmented rates of splanchnic uptake of gluconeogenic precursors and production of glucose in response to fructose infusion were observed in parallel with a significant renal release of lactate and pyruvate. The rates of renal production of lactate and pyruvate at the end of the study equalled the increments in their splanchnic uptake. These observations, therefore, indicate that the kidneys (by virtue of fructose-derived lactate and pyruvate production) and liver (due to lactate, pyruvate, and fructose-derived glucose production) both contribute to fructose-induced hyperglycemia in insulin-deficient diabetes.

In healthy subjects fructose infusion was accompanied by significant renal production of glucose, lactate, and pyruvate, indicating conversion of fructose to these compounds by the kidneys and thus confirming previous findings in subjects who fasted $60 \mathrm{~h}$ (14). The present results (Figs. 3 and 4, Tables II and III) demonstrate that during fructose infusion in healthy men, fructose-derived renal glucose production accounts for 
one-third of glucose turnover. Furthermore, fructose-derived renal lactate and pyruvate formation is responsible for $25 \%$ of the increase in their arterial levels. In diabetics hyperglycemia with an accompanying urinary glucose loss prevented us from using renal glucose exchange as a reflection of glucose production by the kidneys. However, the maximal rate of fructose-derived renal glucose production can be estimated indirectly from simultaneous measurements of urinary excretion and renal uptake of fructose in combination with renal exchange of lactate, pyruvate, and alanine. Such estimations show that of the fructose taken up $(0.74 \mathrm{mmol} / \mathrm{min}) \sim 0.25 \mathrm{mmol} / \mathrm{min}$ is lost in the urine, leaving $0.49 \mathrm{mmol} / \mathrm{min}$ to represent the amount metabolized. Renal release of lactate, pyruvate, and alanine together amounted to $0.24 \mathrm{mmol} / \mathrm{min}$ (calculated as glucose equivalents; Table III). The unaccountable portion of renal fructose metabolism is then $0.25 \mathrm{mmol} / \mathrm{min}$ and represents the maximal rate of fructose-derived renal glucose production. This value is close to that obtained from direct measurements in control subjects. We therefore conclude that the kidneys play a quantitatively important role in the formation of end products of fructose metabolism after infusion in both insulin-deficient, diabetic patients and control subjects.

Although the present study involved measurements of only some of the potential end products of hepatic fructose metabolism, a comparison between the results obtained in diabetics and controls should provide some insight into the role of insulin in the regulation of intermediary hepatic fructose metabolism. The major end products of hepatic fructose metabolism are glucose, lactate, and glycogen $(7,8,12)$. In addition, fructose-derived oxidation and lipogenesis by the liver must be considered when the fate of hepatic fructose metabolism is discussed. The remaining theoretically possible end products of hepatic fructose metabolism are glycerol and sorbitol. However, fructose-derived glycerol and/or sorbitol production by the liver was probably essentially absent in the present study since it appears to occur only when the redox state of the hepatocyte is disturbed by ethanol administration (8).

The simultaneous measurement of splanchnic exchange of fructose, glucose, and gluconeogenic precursors allowed us to evaluate the theoretical metabolic fate of the extracted fructose. In the diabetics splanchnic uptake of gluconeogenic precursors including fructose (expressed as glucose equivalents) exceeded the production of glucose by $0.5 \mathrm{mmol} / \mathrm{min}$ (Table V). In the controls the release of glucose was much smaller; instead, lactate and pyruvate were released during fructose infusion. In control subjects fructose uptake exceeded total release of substrates by $1.0 \mathrm{mmol} / \mathrm{min}$. These observations, therefore, indicate that insulin deficiency is accompanied by a $50 \%$ reduction of the amount of fructose available for glycogen synthesis, oxidation, and/or lipogenesis in the splanchnic tissues.

While the present study allows us to conclude that the major end product of hepatic fructose metabolism in insulindeficient diabetic patients is glucose, no firm conclusion can be drawn as to the metabolic fate of the major proportion of the fructose taken up by splanchnic tissues in controls. However, fructose infusion in normal man at rates slightly higher (20-80\%) than in the present study has been shown to result in a substantial accumulation of hepatic glycogen $(494 \mathrm{mmol}$ in 4 h or $2.1 \mathrm{mmol} / \mathrm{min}$ ) (12). If one assumes that $50 \%$ of the fructose infused $(6.6 \mathrm{mmol} / \mathrm{min})$ was taken up by splanchnic tissues in that study, the proportion of hepatic fructose uptake used for glycogen synthesis becomes $64 \%$, which is similar to the proportion available in the present study (54\%). Thus, the excellent agreement between directly measured and indirectly estimated fructose-derived glycogen formation suggests that a large proportion of the fructose taken up by splanchnic tissues is converted to hepatic glycogen. Although it should be emphasized that alternate fates of hepatic fructose metabolism (lipogenesis and/or oxidation) cannot be excluded, it is likely that the major part of the difference between diabetics and controls regarding the amount of fructose not accounted for by substrate release reflects different rates of hepatic glycogen synthesis. The present results, therefore, suggest that the capacity for fructose-derived hepatic glycogen synthesis is reduced in insulin-deficient diabetics. The findings further indicate that this reduction is associated with the acute withdrawal of insulin administration since replacement of insulin in two diabetics normalized all responses to fructose infusion (Table IV).

The present findings indicate that fructose infusion does not exert an antiketogenic influence in insulin-deficient diabetic patients. Thus, fructose infusion failed to alter both arterial levels (Table II) and splanchnic production (Table III) of ketones. Furthermore, splanchnic ketone production was similarly related to splanchnic FFA inflow in the basal state and during fructose infusion (Fig. 5). Consequently, under the present experimental conditions there was no evidence of an inhibitory influence of fructose on splanchnic ketone production.

These results are in apparent conflict with those reported by Dietze et al. using similar techniques (15). In their study fructose infusion in type I diabetic patients was accompanied by a fall in ketone levels resulting from an inhibition of hepatic ketone production. This response could not have been the consequence of reduced hepatic availability of FFA since both FFA levels and splanchnic blood flow rose, indicating an effect on the intrahepatic ketogenic process. The degree of ketosis was higher in the present as compared with the previous study. It is possible that the effect of fructose administration on hepatic ketone body formation is dependent on the degree of prevailing ketosis and that this explains the different results. In control subjects fructose infusion exerted an antiketogenic effect as indicated by the fall in both arterial levels and splanchnic production of ketones. It is probable that this was mainly the consequence of the accompanying rise in insulin levels. The response was caused by both a fall in FFA levels (Table II) and an inhibition of the rate of ketone production, as illustrated by the flat slope of the relation between splanchnic FFA inflow and ketone production (Fig. 5).

The present simultaneous measurements of splanchnic and renal fructose exchange ( $\sim 2$ and $0.8 \mathrm{mmol} / \mathrm{min}$, respectively) indicate that these tissues account for $60-70 \%$ of fructose disposal, leaving some $30-40 \%$ unaccounted for. There is evidence that skeletal muscle has the capacity to extract and metabolize fructose, probably by virtue of phosphorylation to fructose-6-phosphate by hexokinase $(27,28)$. Thus, it is likely, particularly in view of the large muscle mass, that muscle is responsible for a major proportion of the fructose disposal that was not accounted for by splanchnic and renal tissues.

In summary, the present findings indicate that both the kidney and the liver contribute to the hyperglycemic response to fructose infusion in insulin-deficient diabetic patients. The metabolic processes involved are increased hepatic gluconeogenesis from fructose, lactate, and pyruvate, and increased re- 
lease of lactate and pyruvate by the kidney. Furthermore, hepatic fructose metabolism under conditions of insulin deficiency results in production and release of glucose rather than formation of lactate, pyruvate, or glycogen. The results also indicate that in insulin-deficient, mildly ketotic diabetic patients fructose does not exert an antiketogenic effect. Finally, the data suggest that intermediary hepatic fructose metabolism is regulated by insulin and that the capacity for fructose-derived hepatic glycogen synthesis is reduced in insulin-deficient diabetics.

\section{References}

1. Kulz, E. 1874. Beitrage zur Pathologie und Therapie des Diabetes Mellitus. N. G. Elwert's Verlag, Marburg. 130-146.

2. Metz, R., M. Mako, T. Stevens, and J. Franklin. 1967. The metabolism of fructose in diabetes mellitus. J. Lab. Clin. Med. 69:494-503.

3. Darragh, J. H., R. A. Womersley, and W. H. Meroney. 1953. Fructose in the treatment of diabetic ketosis. J. Clin. Invest. 32:12141221.

4. Smith, L. H., R. H. Ettinger, and D. Seligson. 1953. A comparison of the metabolism of fructose and glucose in hepatic disease and diabetes mellitus. J. Clin. Invest. 32:273-282.

5. Miller, M., J. W. Craig, W. R. Drucker, and H. Woodward. 1956. The metabolism of fructose in man. Yale J. Biol. Med. 29:335360.

6. Wolfe, B. M., S. P. Ahuja, and E. B. Marliss. 1975. Effects of intravenously administered fructose and glucose on splanchnic amino acid and carbohydrate metabolism in hypertriglyceridemic men. $J$. Clin. Invest. 56:970-977.

7. Craig, J. W., W. R. Drucker, M. Miller, J. E. Owens, H. Woodward, B. Brofman, and W. H. Pritchard. 1951. Metabolism of fructose by the liver of diabetic and non-diabetic subjects. Proc. Soc. Exp. Biol. Med. 78:698-702.

8. Tygstrup, N., K. Winkler, and F. Lundquist. 1965. The mechanism of the fructose effect on the ethanol metabolism of the human liver. J. Clin. Invest. 44:817-830.

9. Elliott, W. C., L. S. Cohen, M. D. Klein, F. J. Lane, and R. Gorlin. 1967. Effects of rapid fructose infusion in man. J. Appl. Physiol. 23:865-869.

10. Mendeloff, A. I., and T. E. Weichselbaum. 1953. Role of the human liver in the assimilation of intravenously administered fructose. Metab. Clin. Exp. 2:450-458.

11. Dietze, G., M. Wicklmayr, J. Grunst, S. Stiegler, and H. Mehnert. 1976. Die Verwertung von Glukose und Fruktose in Leber and Muskel beim Menschen. Int. J. Vitam. Nutr. Res. Suppl. 15:31-43.

12. Nilsson, L., H:son, and E. Hultman. 1974. Liver and muscle glycogen in man after glucose and fructose infusion. Scand. J. Clin. Lab. Invest. 33:5-10.

13. Heinz, F., F. Schlegel, and P. H. Krause. 1975. Enzymes of fructose metabolism in human kidney. Enzyme (Basel). 19:85-92.

14. Björkman, O., and P. Felig. 1982. Role of the kidney in the metabolism of fructose in 60-hour fasted humans. Diabetes. 31:516520.

15. Dietze, G., M. Wicklmayr, and H. Mehnert. 1978. Antiketogenic action of fructose in man. Diabetes. 27:709-714.

16. Brun, A. 1951. A rapid method for the determination of paraamino-hippuric acid in kidney function tests. J. Lab. Clin. Med. 37:955-958.

17. Rowell, L. B., J. R. Blackmon, and R. A. Bruce. 1964. Indocyanine green clearance and estimated hepatic blood flow during mild to maximal exercise in upright man. J. Clin. Invest. 43:1677-1690.

18. Huggett, A. S. G., and D. A. Nixon. 1957. Use of glucose oxidase, peroxidase and $O$-dianisidine in determination of blood and urinary glucose. Lancet. ii:368-370.

19. Berndt, E., and H. U. Bergmeyer. 1974. D-Fructose. In Methods of Enzymatic Analysis. H. U. Bergmeyer, editor. Academic Press, Inc., New York. 1304-1307.

20. Hohorst, H. J. 1970. L-(+)-Lactat: Bestimmung mit LactatDehydrogenase und NAD. In Methoden der Enzymatische Analyse. H. U. Bergmeyer, editor. Verlag Chemie GmbH, Weinheim, West Germany. 1425-1429.

21. Bücher, R., R. Czok, W. Lamprecht, and E. Latzko. 1962. Pyruvat. In Methoden der Enzymatischen Analyse. H. U. Bergmeyer, editor. Verlag Chemie GmbH, Weinheim, West Germany. 253-257.

22. Wieland, O. 1962. Glycerin. In Methoden der Enzymatischen Analyse. H. U. Bergmeyer, editor. Verlag-Chemie GmbH, Weinheim, West Germany. 211-215.

23. Williamson, D. H., J. Mellanby, and H. A. Krebs. 1962. Enzymatic determination of $D$ (beta)-hydroxy butyric acid and aceto-acetic acid in blood. Biochem. J. 82:80-96.

24. Hagenfeldt, L. 1966. A gaschromatographic method for the determination of individual free fatty acids in plasma. Clin. Chim. Acta. 13:266-268.

25. Hjemdahl, P., M. Daleskog, and T. Kahan. Determination of plasma catecholamines by high performance liquid chromatography with electrochemical detection: comparison with a radioenzymatic method. Life Sci. 22:131-138.

26. Wahren, J., P. Felig, E. Cerasi, and R. Luft. 1972. Splanchnic and peripheral glucose and amino acid metabolism in diabetes mellitus. J. Clin. Invest. 51:1870-1878.

27. van Itallie, T. B., M. C. Morgan, R. T. Cathcart, G. G. Leduc, and L. B. Dotti. 1953. Peripheral assimilation of fructose in man. Proc. Soc. Exp. Biol. Med. 84:713-715.

28. Wicklmayr, M., G. Dietze, B. Günther, H. Schöps, W. Hartl, and $H$. Mehnert. 1983. Untersuchungen zur Verwertung von Fruktose durch die menschliche Skelettmuskulatur. Aktuel. Ernähr. 8:192-199. 